\title{
Modeling the Roles of Leadership for Inter-organizational Information Sharing and Integration Success
}

\author{
Djoko Sigit Sayogo \\ University of Muhammadiyah Malang \\ JI. Raya Tlogomas no. 246 \\ Malang, Indonesia \\ dsayogo@ctg.albany.edu
}

\author{
J. Ramon Gil-Garcia \\ University at Albany, SUNY \\ 187 Wolf road, Suite 301 \\ Albany, New York \\ jgil-garcia@ctg.albany.edu
}

\author{
Theresa A. Pardo \\ University at Albany, SUNY \\ 187 Wolf road, Suite 301 \\ Albany, New York \\ tpardo@ctg.albany.edu
}

\begin{abstract}
We expand the current understanding of leadership's influence on the success of inter-organizational information sharing and integration (IIS) by testing and proposing direct and indirect relationships using structural equation modelling (SEM). We analyzed data from a national survey of 173 professionals from IIS projects in Public Health and Criminal Justice in the US. We evaluated the direct and indirect relationships of three leadership mechanisms - executive involvement, exercise of formal authority, and informal leaders. By testing the causal relationships between two types of leaders: bureaucratic-based executive leader and network-based informal leaders, we substantiate how embeddedness in bureaucracy influences the relationship between leadership activities and success of IIS projects. Our findings show the significant role of executive involvement to the success of IIS. We found that the influence of informal leaders is magnified by the involvement of executives. Our finding also support the importance of informal leaders both directly to the success of IIS or in curbing the potential negative impact of misuse of authority in the collaboration. Finally, we found that perceptions of participants in terms of how IIS project success is measured, influences the impact of leadership on the success of IIS projects.
\end{abstract}

\section{CCS Concepts}

social and professional topics - technology policy - government technology policy - governmental regulations

\section{Keywords}

Inter-organizational information sharing, information integration, leadership, executive involvement, informal leaders, network.

\section{INTRODUCTION}

Advancement in Information and Communication Technologies (ICTs) has created new capabilities for collaboration and problem solving. ICTs provide capabilities for coordination,

Permission to make digital or hard copies of all or part of this work for personal or classroom use is granted without fee provided that copies are not made or distributed for profit or commercial advantage and that copies bear this notice and the full citation on the first page. Copyrights for components of this work owned by others than ACM must be honored. Abstracting with credit is permitted. To copy otherwise, or republish, to post on servers or to redistribute to lists, requires prior specific permission and/or a fee. Request permissions from Permissions@acm.org.

dg.o '16, June 08-10, 2016, Shanghai, China

(C) 2016 ACM. ISBN 978-1-4503-4339-8/16/06 ...\$15.00

DOI: http://dx.doi.org/10.1145/2912160.2912203. continued engagement, access to data and sharing of information that are crucial for handling complexities and uncertainties [20]. ICTs also support the collective capabilities of agencies, private entities and general public to organize, interact, and govern as they work to overcome increasingly complex social challenges [12]. Foremost, this capability resides within the ability of ICTs to promote and support information integration and sharing (IIS) across various domains and beyond the boundary of individuals, units and organizations [3]. Capabilities for integrating and sharing of information are the foundation of government efforts to develop and execute public policies that are smart, efficient and more responsive to nowadays social problems $[3,20]$.

Examined from an organizational perspective, integrating and sharing information across different organizations and/or units has the potential to support the transformation of organizational structures and communication channels among multiple agencies working in different locations. It allows managers in different places to work at the same time, with the same information amalgamated from multiple disparate sources $[10,15]$. Integrating and sharing information across boundaries is recognized as generating new technical, organizational and political benefits for those entities involved [3, 4, 21]. The number of participating organizations and individuals involved in such efforts contributes to their complexity. Managing such complexity with the goal of implementing an IIS initiative benefits from the use of collaborative networks involving various organizations [3, 4]. Working on an IIS initiative within such a collaborative network setting might pose challenge for government officials, who were unaccustomed to working collaboratively across their respective agency's boundary [3]. This subsequently raises a number of important questions about how leadership and authority are exercised in governing such collaborative efforts $[8,10,15]$.

The challenges facing the leadership of IIS initiatives are significant due to the embeddedness of such initiatives in larger political and institutional environments which shape their goals and circumscribe their choices $[5,10,15,23]$. As argued by Eglene et al [8], although IIS initiatives are often organized in a network setting, each participant involved in IIS still obtain authority from and are accountable to the traditional bureaucratic environment of their own agencies. This condition makes the organizing functions of IIS projects unique because it connects both network and bureaucratic forms of governance; including the possible coexistence of two different forms of leadership - network and bureaucracy [8]. Subsequently, it has also been argued that leadership in inter-organizational information sharing and integration is exercised through three activities - executive involvement, exercising of formal authority, and informal leadership [10, 15]. According to Huxham and Vangen [11], 
leadership can be shaped through process and exercised through activities in a collaboration. As such, we define leadership as the activities or mechanisms to exercise leadership to sustain the collaboration. We measure leadership using three activities: (1) executive involvement, (2) exercising of formal authority, and (3) informal leadership. Following the argument put forward by Eglene et al [8] that success of IIS can be defined in various ways and might manifest in compounding layers, we measure IIS success through the use of three categories: a) project overall is a success, b) project achieves technological success, and c) project meets its policy objectives.

This paper provides new understanding of the influence of leadership on the success of multi-sector collaboration in information sharing and integration initiatives. This study addresses two research questions: a) how do different leadership activities affect the success of inter-organizational information sharing and integration (IIS) and b) given that IIS collaboration is embedded in bureaucracy, how do bureaucratic-based mechanisms influence the success of IIS in relation to other leadership activities? We expand existing work on leadership in IIS (see for instance, $8,10,15)$ in three ways. First, we provide an evaluation on the causal relationships between leadership and the success of IIS based on statistical analysis. Second, we base our arguments on the analysis of a national survey of 173 professionals of IIS projects in Public Health and Criminal Justice; thus the result may expand the generalizability of findings beyond existing literature. Third, we evaluate the differentiated impact of different mechanisms of leadership on IIS success. Eglene et al., [8] propose nine (9) hypotheses of leadership and authority in IIS networks in which four (4) of the hypotheses postulate the significance of bureaucracy in exercising leadership roles. Our analysis tests whether bureaucracy and bureaucratic leadership mechanisms are more dominant than other types of leadership mechanisms in the success of IIS.

\section{Leadership, Authority and the Success of IIS}

Leadership and authority receive significant attention in the study of inter-organizational information sharing and integration (IIS). The social processes that signify the employment of leadership functions, such as conflict resolution, decision making, and collaboration are argued as crucial elements of IIS success [16]. Huxham and Vangen [11] argue that leadership in collaborative efforts is a fluid concept that is not only tied to people but also structure and process. As such, we define leadership in terms of the mechanisms used to exercise it, and in particular, adopt Pardo et al.'s [15] and Gil-Garcia et al.'s [10] framing of leadership in terms of three mechanisms: executive involvement, exercising formal authority, and informal leadership.

Involvement and support from executives is critical for the success of inter-organizational information sharing in the public sector $[3,5,8,10,13,15]$. In contrast, lack of support from executives is associated with the failure of inter-organizational information sharing [22]. At the initial stage of inter-organizational information sharing and integration, the involvement of elected or career-based executives provides legitimating authority for the collaborative network [4, 6]. This is crucial because authority develops gradually in collaborative networks [18]. Hence, executive involvement is necessary to provide formal legal authority [4].
Subsequently, the roles of executive involvement changes throughout the implementation process of IIS projects. To sustain collaboration across multiple implementation stages, the executive is expected to change their role [4]. There are two main roles that executive involvement is expected to fulfill during the implementation stage. The first role is to secure financial resources for the project. The involvement of executives in negotiating bureaucratic processes for budget and financial purposes is vital to the implementation and success of IIS initiatives [4, 8]. Second, executive involvement is needed for coaxing coordination in collaborative networks. Pardo et al., [15] and Gil-Garcia et al., [10] assert that executives manage coordination in three ways: a) inciting the willingness of the key actors to participate, b) demonstrating the respect for the autonomy of participating organization, and c) supporting the action of informal leaders. Thus, executive involvement influences the success of interorganizational information sharing and integration directly, but also indirectly through informal leaders.

Thus, although overall project leaders, as argued by Dawes \& Pardo [5], are a critical factor in the success of collaborative initiatives, the role of informal leaders is no less crucial. While according to Landsbergen \& Wolken [13] overall project leaders provide overarching support and sponsorship, informal leaders work at the operational level to get projects going [10, 15]. For instance, informal leaders are recognized as the ones who nurture trust building among the participants [9], mitigate potential conflicts and sustain coordination among the diverse participants $[10,15]$. In ensuring coordination among the participants, these informal leaders use boundary objects and mitigate localized and episodic problems to develop shared understanding. They also clarify roles and responsibilities and contribute to the development of appropriate and effective strategies to minimize conflict and resistance $[10,15]$.

The leadership function in an IIS collaboration is also carried out through the exercise of formal authority in the collaboration. Consequently, how the leader exercises authority affects the development of shared understanding and the mitigation of potential conflicts in a collaborative effort [4, 8, 10, 14, 15]. Thoughtful exercise of formal authority alleviates possible frictions among the participants, helps build trust, and provides a foundation for collaborative efforts in IIS [14]. Attentiveness in exercising formal authority fosters willingness to participate in the implementation and eventually success of IIS $[10,15]$. On the contrary, when the leader is inconsistent in exercising their formal authority it can stimulate friction and resistance, which eventually hampers the success of an IIS project [10, 15]. Furthermore, it is argued that conscientious way of exercising formal authority can be done by the involvement of executives and/or by the informal leaders in the collaboration [10, 15]. As argued by Pardo et al., [15], the use of formal authority by executives in making resources available, promoting participation and respecting the autonomy of participating organizations encourages willingness to participate which eventually leads to success.

In conclusion, extant studies show both direct and indirect influence of leadership on the success of inter-organizational information sharing and integration. As shown in our review of the literature, executive involvement affects the success of interorganizational information sharing and integration directly and indirectly. 


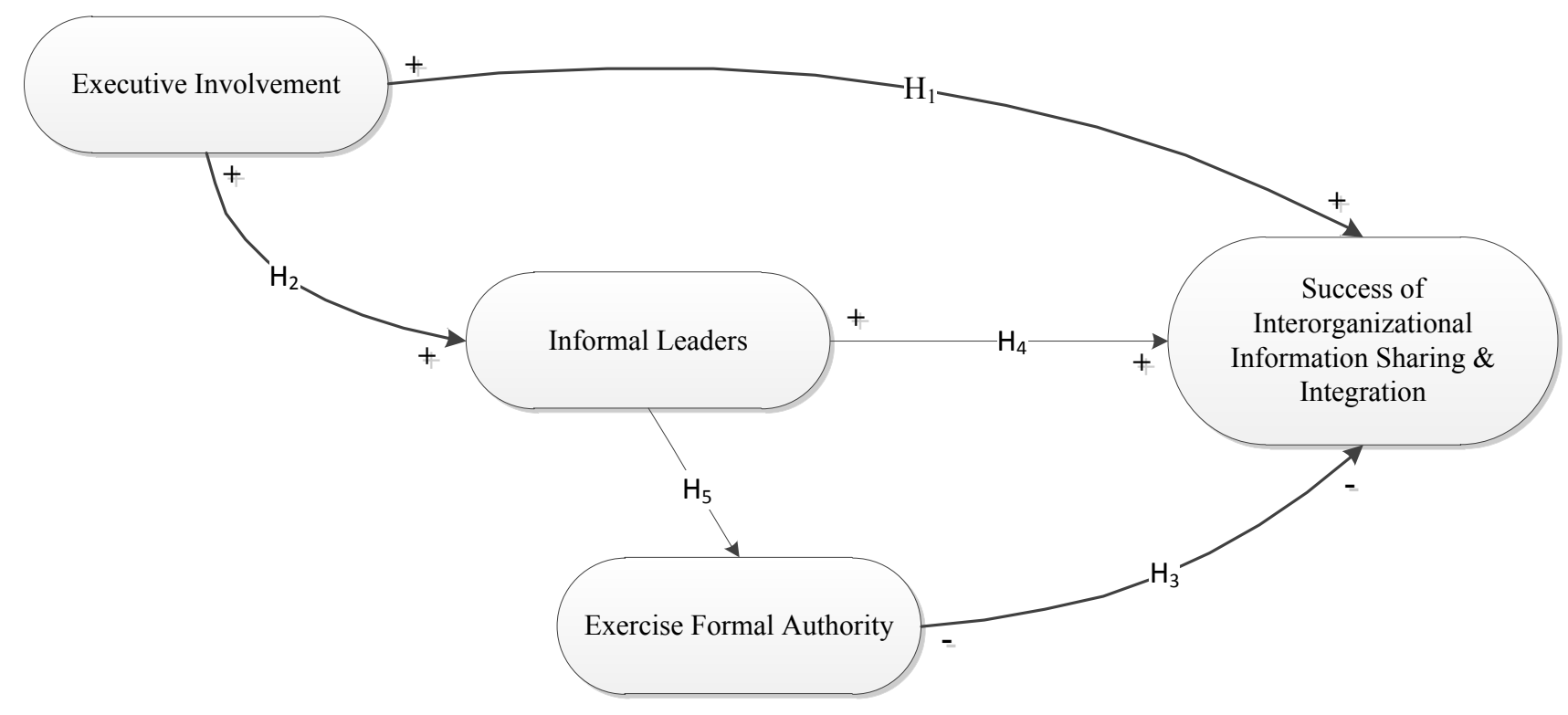

Figure 1. The Tested Model of Leadership Influence to IIS Success

Directly, the involvement of executives is crucial for providing the necessary resources and the assurance that autonomy is respected. Likewise, executive involvement also influences success by supporting the actions of informal leaders. In turn, the actions of informal leaders also affect the success of IIS through the efforts of those informal leaders in maintaining the network and necessary levels of coordination. In addition, informal leaders play a role in facilitating the exercise of formal authority and the consideration of the respective autonomy of the various participants. Finally, how leaders exercise their authority directly influences success through the development of shared understanding and the mitigation of potential conflicts in the collaboration. Hence, we propose a model of the leadership influence on IIS success (See figure 1) and hypothesize 5 causal relationships between leadership mechanisms and the success of inter-organizational information sharing.

- Hypothesis 1: Involvement of executives positively and directly influences the success of inter-organizational information sharing and integration.

- Hypothesis 2: The positive impact of executive involvement to the success of inter-organizational information sharing and integration is mediated by the roles of informal leaders.

- Hypothesis 3: The inconsiderate conducts in exercising formal authority influences the success of inter-organizational information sharing and integration directly and negatively.

- Hypothesis 4: The role of informal leaders directly and positively influences the success of inter-organizational information sharing and integration.

- Hypothesis 5: The impact of informal leaders to the success of inter-organizational information sharing and integration is mediated by the conduct in exercising formal authority.

\section{Research Design and Method}

This section briefly describes the research and methods used for this study, including the data collection, the variable measurements and the analysis techniques. The paper is based on a survey data. Considering our interest to test the direct and indirect relationships linking the leadership mechanisms and success of III, the data was analyzed using Structural Equation Modeling techniques to account for the endogenous - exogenous relationships among the variables. The following subsections provide more detail about our data and analysis techniques.

\subsection{Data and Data Collection}

This study analyzes data from a national survey conducted by the Center for Technology in Government (CTG) in April 2008. When aiming to test theory, the use of older data does not present a problem, as it is expected that the relationship among the variables, if shown, is generalizable and stable over time. The original dataset consists of 173 responses with demographic distribution as shown in Table 1.

Table 1. Sample Distribution

\begin{tabular}{llr}
\hline & Categories & $\mathbf{\%}$ \\
\hline Employment & Federal Agencies & $5 \%$ \\
& Local Agencies & $56 \%$ \\
& State Agencies & $29 \%$ \\
& Private Entities & $3 \%$ \\
& NGOs & $4 \%$ \\
& Academics & $1 \%$ \\
& Other (e.g., independent consultant) & $2 \%$ \\
& & \\
Position & Executive & $35 \%$ \\
& IT Manager & $12 \%$ \\
& IT Staff & $1 \%$ \\
& Program Manager & $35 \%$ \\
& Program Staff & $10 \%$
\end{tabular}




\section{Administrative Staff}

Initiative's

Across units

$7 \%$

boundary

Across agencies at the same level of

$23 \%$

government

Across levels of government

Across one level of government with

$33 \%$

non-government organization(s)

Across multiple levels of government

with non-government organization(s)

Other (e.g. multi-nationals)

Primary

Federal government

$6 \%$

Initiative

State government

$61 \%$

Coordinator

Local government

Private entities

Non-profit organization

Other (e.g. council of government)

\begin{tabular}{llr} 
Years of & 0 years & $3 \%$ \\
Experience & $1-5$ years & $39 \%$ \\
& $6-15$ years & $45 \%$ \\
& $16-25$ years & $10 \%$ \\
& $>25$ years & $3 \%$ \\
\multirow{2}{*}{ Sex } & & \\
& Female & $42 \%$ \\
& Male & $58 \%$ \\
\hline
\end{tabular}

After data cleansing, the analysis was based on 158-160 responses and about $7-8 \%$ of the responses were dropped from the analysis due to high levels of missing values. The majority of survey respondents work for local governments (56\%), followed by state governments $(29 \%)$. The majority of these respondents have positions as executives $(35 \%)$ or program managers $(35 \%)$. The proportion of male respondents was higher than female respondents by $16 \%$. Almost all respondents have acquired some experience working in their respective field for at least one year, with only 3\% of the respondents indicating that they had not yet acquired some experience at the time of the survey.

\subsection{Variable Measurements}

In accordance with our model in Figure 1, we are interested in testing the influence of three variables on the success of IIS, namely; executive involvement, informal leaders, and exercise of formal authority. The description and measurement of each variable is provided below:

a. Exercise of formal authority. We use a negative measure for exercise of authority. The question asked was whether leaders and/or participants misused the power of their official positions. This variable is measured in a 7-point Likert scale.

b. Informal leaders. This variable measures the role of informal leaders in IIS projects. This is a composite variable combining two constructs. Questions asked were a) how participants went beyond their official duties in terms of leadership, and $b$ ) how participants took on coordination or problem-solving responsibility beyond their official duties. Both questions are measured in 7-point Likert scales. We run Chronbach's alpha to test the reliability of the measurement of this variable and the result is 0.9442 which indicates excellent reliability well above the threshold of 0.70 . c. Executive involvement. This variable is also a composite variable measuring the role, sponsorship and support of executives for an IIS project. We use the following three constructs to measure the variable: a) the support from elected officials (other than legislators), b) the sponsorship from highlevel executive, and c) the support from relevant individual executives. The reliability of this variable in terms of Chronbach's alpha is 0.7353 which is still above the threshold of 0.70 .

d. Success of Inter-organizational Information Sharing and Integration. Adopting Eglene et al.'s [8] argument, the success variable is measured in three ways, as follows.

- Overall success. This variable measures whether the IIS participants deem that, taken as a whole, the project was a success. This variable is measured in a 7 point Likert scale ranging from "Not at all (1)" to "To a great extent (7)".

- Met the policy objectives. This is a 7-point Likert scale variable measuring whether the participants agree that the project met its stated policy objectives and goals. The values also ranged from "Not at all (1)" to "To a great extent (7)".

- Technology success. This is a composite variable consisting of three constructs measuring technology success. The construct asks the participants whether they agree that the project is a success technologically in terms of creating: a) information systems that can communicate with each other, b) interoperable computer systems and networks and c) an integration of disparate databases into new data resources. Each of the constructs is measured in a 7-point Likert scale. The reliability of this variable measured by Chronbach's alpha is 0.8757 .

- Organizational success. We define this variable as measurement of success in terms of the benefits that IIS brings to the organization. We measure the benefits to organizations in 5 ways: a) improvement in the day-by-day operations of government, b) greater effectiveness of policy deliberation, c) improved efficiency, d) direct benefits to people, group and organization, and e) cost savings. This is also a reliable composite variable with Chronbach's alpha of 0.8589 .

\subsection{Analysis Techniques}

Data analysis in this study was conducted in two stages. The first stage created the composite variables using principal component factor analysis. The reliability of the resulting variables was examined using Chronbach's alpha values (Table 2). As mentioned previously, all the Chronbach's alpha values were above 0.70 , representing acceptable levels of reliability. The second stage tested the structural model. We employed the structural equation modelling approach using Lisrel 8.80. To analyze the fit of the model, we used several information criteria as presented in Table 4.

Table 2. Means and Chronbach's Alpha Values

\begin{tabular}{llcc}
\hline \multicolumn{1}{c}{ Variables } & abb & $\begin{array}{c}\text { ii-cor* } \\
/\end{array}$ & $\boldsymbol{\alpha}$ \\
\hline 1. Executive Involvement & Exec & 1.382 & 0.7353 \\
2. Informal Leaders & Info & 1.678 & 0.9442 \\
3. Technological success & Tech & 3.409 & 0.8757 \\
4. Organizational success & Org. & 1.551 & 0.8589
\end{tabular}


5. Exercise of authority

Auth

1.563

6. Overall success

Suc

5.783

7. Met stated policy objectives

Poli

5.726

* ii-cor refers to average of interrelation correlation

\section{RESULTS AND DISCUSSION}

This section presents the results of our analysis. First, we explain how the success of inter-organizational information sharing is measured. Then, we present the results in terms of the overall model goodness of fit. Finally, this section explains the impact of each of the leadership variables on IIS success and some of the relationships among them.

\subsection{Measuring Success in Inter-organizational Information Sharing and Integration}

There are various ways to define the success of a collaborative project from the perceptions of different project's stakeholders [8, 17]. Similarly, as inter-organizational information sharing and integration projects are often conducted in collaboration, each stakeholder could have different perceptions of success. We then measure success from three interrelated components of IIS, namely: policy, technology and organization. In addition we also measure the overall project success.

Our results indicate that the majority of respondents (93\%) agree to a certain degree $(25 \%)$ or to a great extent $(69 \%)$ that taken as a whole, the IIS project was a success. We found similar results when success is measured by the fact that the project met its stated policy and goals with $67 \%$ agree to a great extent and $26 \%$ agree to a certain degree. However, we found different results for technological and organizational success. Overall, the indicators for technology and organization show that in average the respondents agree to a certain degree $(24 \%-29 \%)$ or to a great extent $(48 \%-56 \%)$ that the project was a success technologically and organizationally. However, we found that close to one third of respondents do not agree or are not sure that the project enables the creation of interoperable systems and networks and the creation of integrated databases into new data resources.
We also found that close to a quarter of the respondents do not agree or are not sure that IIS projects result in an organization having greater effectiveness in deliberating policy and in achieving costs saving.

\subsection{Model Fit}

We measured whether our proposed theoretical model (Figure 1 ) is a fit model based on the survey data. We present the goodnessof-fit measure in Table 4.

Table 4. Model Goodness-of-fit

\begin{tabular}{|c|c|c|c|c|c|}
\hline \begin{tabular}{l}
\multicolumn{1}{c}{ Model } \\
goodness-of- \\
fit indexes
\end{tabular} & $\begin{array}{c}\text { Cut- } \\
\text { off } \\
\text { values }\end{array}$ & $\begin{array}{l}\text { Overall } \\
\text { Success }\end{array}$ & $\begin{array}{c}\text { Policy } \\
\text { Success }\end{array}$ & $\begin{array}{l}\text { Tech. } \\
\text { Success }\end{array}$ & $\begin{array}{c}\text { Org. } \\
\text { Success }\end{array}$ \\
\hline$\chi^{2}$ & $\begin{array}{c}< \\
\chi^{2} \text { table }\end{array}$ & 1.576 & 1.595 & 1.605 & 1.953 \\
\hline $\begin{array}{l}\chi^{2} \text { significance } \\
\text { (p) }\end{array}$ & $p>.05$ & 0.209 & 0.207 & 0.205 & 0.162 \\
\hline $\begin{array}{l}\text { Goodness-of- } \\
\text { fit index (GFI) }\end{array}$ & $\geq 0.90$ & 0.995 & 0.995 & 0.995 & 0.994 \\
\hline $\begin{array}{l}\text { Normed fit } \\
\text { index (NFI) }\end{array}$ & $\geq 0.90$ & 0.974 & 0.975 & 0.958 & 0.971 \\
\hline $\begin{array}{l}\text { Comparative } \\
\text { Fit Index }\end{array}$ & $\geq 0.90$ & 0.989 & 0.990 & 0.981 & 0.984 \\
\hline $\begin{array}{l}\text { Incremental } \\
\text { Fit Index (IFI) }\end{array}$ & $\geq 0.90$ & 0.990 & 0.991 & 0.984 & 0.985 \\
\hline RMR & $\leq 0.10$ & 0.030 & 0.031 & 0.029 & 0.033 \\
\hline RMSEA & $\leq 0.10$ & 0.059 & 0.060 & 0.061 & 0.075 \\
\hline $\begin{array}{l}\text { p-value of } \\
\text { RMSEA }\end{array}$ & $p>.05$ & 0.297 & 0.295 & 0.294 & 0.247 \\
\hline
\end{tabular}

The results indicate that in all models, the fitness test signifies an adequate fit. Results from the structural analysis indicate that the tested models provide adequate explanations for the structural relationships among variables.

\section{Table 3. The Measurement of IIS Success}

\begin{tabular}{|c|c|c|c|c|c|}
\hline \multirow[b]{2}{*}{ Indicator of Success } & & \multicolumn{4}{|c|}{ Degree of Success } \\
\hline & & $\begin{array}{c}\text { Not at } \\
\text { all }\end{array}$ & $\begin{array}{l}\text { Not } \\
\text { sure }\end{array}$ & $\begin{array}{c}\text { To } \\
\text { certain } \\
\text { degree }\end{array}$ & $\begin{array}{r}\text { To a } \\
\text { great } \\
\text { extent }\end{array}$ \\
\hline The project was a success as a whole & Overall & $5 \%$ & $2 \%$ & $25 \%$ & $69 \%$ \\
\hline The project met its stated policy & Policy & $5 \%$ & $2 \%$ & $26 \%$ & $67 \%$ \\
\hline Information System that can communicate with each other & & $17 \%$ & $4 \%$ & $21 \%$ & $57 \%$ \\
\hline Interoperable systems and networks & Technology & $25 \%$ & $4 \%$ & $29 \%$ & $42 \%$ \\
\hline Integration of disparate database & & $28 \%$ & $5 \%$ & $22 \%$ & $44 \%$ \\
\hline Improvement of government daily operation & & $13 \%$ & $6 \%$ & $23 \%$ & $58 \%$ \\
\hline Benefit directly to person, group and organization & & $5 \%$ & $3 \%$ & $24 \%$ & $68 \%$ \\
\hline Greater effectiveness of policy deliberation & Organization & $12 \%$ & $8 \%$ & $38 \%$ & $43 \%$ \\
\hline Improved efficiency & & $9 \%$ & $2 \%$ & $20 \%$ & $69 \%$ \\
\hline Cost savings & & $15 \%$ & $7 \%$ & $37 \%$ & $42 \%$ \\
\hline
\end{tabular}


For instance, the $\chi 2$ value on average for the four models is 1.5 which is lower than the $\chi 2$ cut-off value of $11.07(\mathrm{df}=5, \mathrm{p}=0.05)$, meaning that the model has a good fit. In another instance, if measured by RMSEA or the "badness of fit" index, the average value is 0.05 indicating an approximate fit of the model.

\subsection{Involvement of Executives and the Success of IIS}

Figure 2 presents significant standardized path coefficients for the overall success model and table 5 presents the structural parameter estimates for the four models. The results indicate strong support for hypothesis 1 and 2 on the influence of executive involvement on the success of IIS.
We also found significant impact of executive involvement on the success of IIS when mediated through the role of informal leaders at 0.99 confidence level with t-value of 4.236 for overall success, t-value of 4.249 for policy success, t-value of 3.258 for technical success and t-value of 5.212 for organizational success. Comparing the coefficient estimates and t-values, the influence of executive involvement on success is stronger when executives assume roles that support informal leaders in the collaboration. The coefficient of the relationship between executive involvement and informal leaders is significant at the 0.01 level with estimates of 0.336 and average t-value of 4.5 .

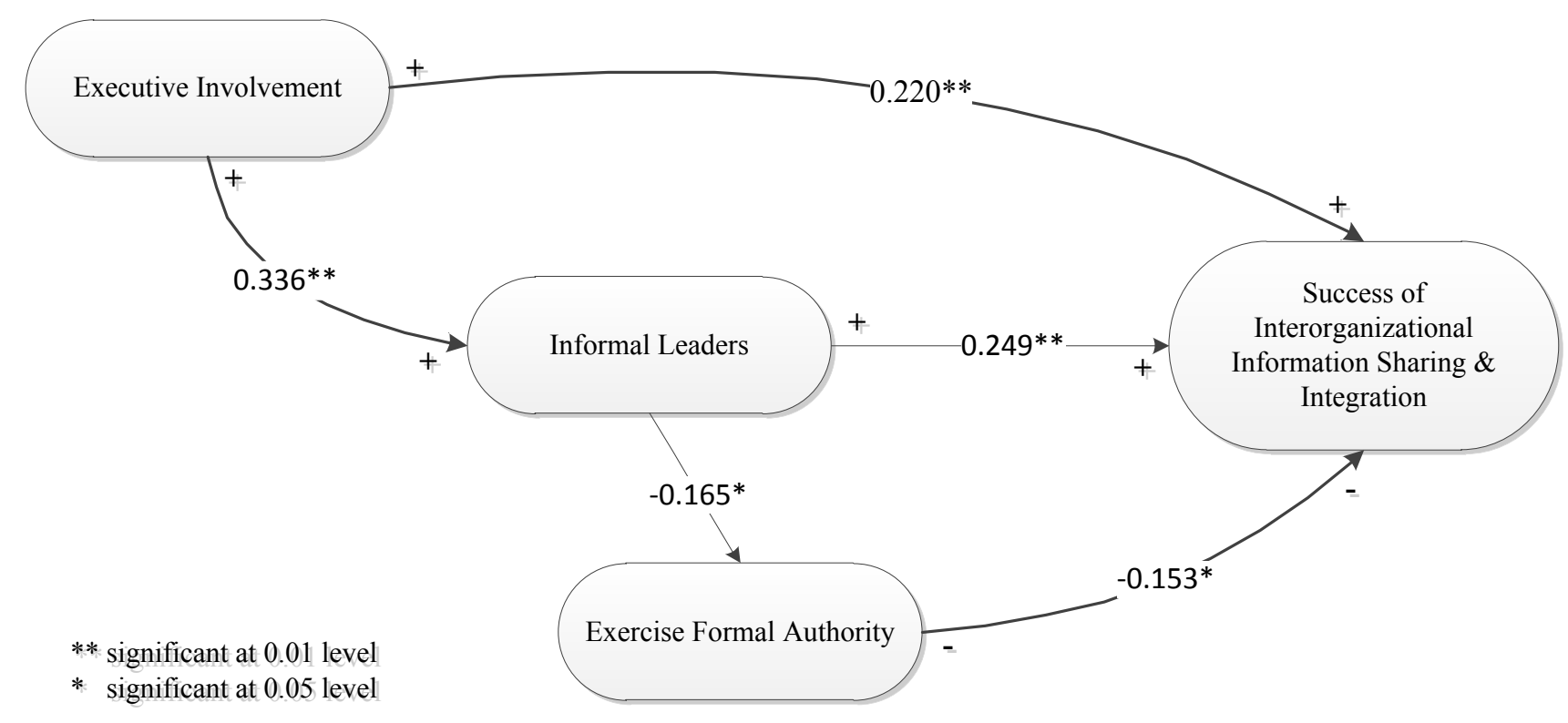

Figure 2. Standardized Path Coefficients for Overall Success

We found positive and significant, direct and indirect relationship between executive involvement and the success of IIS projects. The results show that executive involvement significantly and directly influences the success of IIS at 0.99 confidence level with t-value of 2.920 for overall success, $t$-value 3.009 for policy success, $t$-value of 2.701 for technical success and t-value of 3.791 for organizational success.

Table 5. Structural Parameter Estimates for the Four Models
In addition, we also found that the coefficient estimates changes depending on the measurement of success. Table 5 shows the coefficient estimates are lower when success is measured as technical as compare to policy, organizational or overall success. Presumably when measured directly, executive intervention through, for instance, the enablement of funding has more merit for technological success than policy success. Likewise, the indirect roles of executive in supporting informal leaders matter more for policy success and for overall success.

\begin{tabular}{lrrrrrrrr}
\hline \multicolumn{1}{c}{ Path Coefficients } & $\begin{array}{c}\text { Overall } \\
\text { Success }\end{array}$ & \multicolumn{2}{c}{ Policy Success } & Tech. Success & \multicolumn{2}{c}{ Org. Success } \\
\hline Executive $\rightarrow$ Success & 0.220 & $* *$ & 0.223 & $* *$ & 0.216 & $* *$ & 0.277 & $* *$ \\
Executive $\rightarrow$ Informal $\rightarrow$ Success & 0.312 & $* *$ & 0.306 & $* *$ & 0.245 & $* *$ & 0.374 & $* *$ \\
Executive $\rightarrow$ Informal $\rightarrow$ Authority & -0.056 & $*$ & -0.056 & $*$ & -0.056 & & -0.054 & \\
Executive $\rightarrow$ Informal & 0.336 & $* *$ & 0.336 & $* *$ & 0.336 & $* *$ & 0.336 & $* *$ \\
Informal $\rightarrow$ Success & 0.249 & $* *$ & 0.211 & $* *$ & 0.078 & & 0.295 & $* *$ \\
Informal $\rightarrow$ Authority $\rightarrow$ Success & 0.274 & $* *$ & 0.249 & $* *$ & 0.088 & & 0.289 & $* *$ \\
Informal $\rightarrow$ Authority & -0.165 & $*$ & -0.165 & $*$ & -0.165 & $*$ & -0.162 & $*$ \\
Authority $\rightarrow$ Success & -0.153 & $*$ & -0.228 & $*$ & -0.058 & & 0.042 & \\
\hline
\end{tabular}


The results also show that executive involvement also matters in influencing the exercise of formal authority. The results indicate a positive total effects when executives involvement is mediated by the informal leaders in addressing the misuse of formal authority by participants. As shown in table 5, the coefficient of informal to authority is -0.165 while the coefficient of executive to informal to authority is -0.056 , indicate an increase in positive effects by 195 percentage points. Meaning that proper intervention from an executive by the mediation of informal leaders in response to an instance of misuse of formal authority in a collaboration network could reduce the potential of project failure.

\subsection{The Role of Informal Leaders for IIS Success}

We found strong support for hypothesis 4 and hypothesis 5 . Our analysis results indicate the prominent role of informal leaders in influencing the success of inter-organizational information sharing and integration initiatives. We found that informal leaders significantly influence the success of IIS, contingent to the indicator of success. If success is measured in terms of success at the overall project level, meeting policy objectives, and organizational success, the results indicate strong direct relationships with coefficient estimates of $0.249,0.211$, and 0.295 respectively, and t-value of 3.266 for overall success, $t$-value of 2.820 for policy success, and t-value of 3.995 for organizational success.

The results also indicate the significant role of informal leaders in curtailing the negative effect of participants' misuse of their formal authority. With support from executive, interventions from informal leaders significantly decrease the potential for misusing formal authority regardless of how success is measured. Consequently, it can be said, interventions by informal leaders designed to check the misuse of formal authority by IIS project participants, could increase the success of IIS. The coefficient estimates of indirect relationship between informal leader to IIS success is 0.025 with t-value 1.508 for overall success and 0.038 with t-value 1.786 for policy success, (significant at 0.1 level).

\subsection{Exercising Formal Authority and the Success of IIS}

Finally, we also found strong support for hypothesis 3. The results indicate that misuse of formal authority decreases the potential of success, when success is measured as overall success and policy success. The coefficient estimate is -0.153 for overall success and -0.228 for policy success. We did not find statistically significant results of the influence of misuse of formal authority to IIS success, when success is measured as technological achievement. Interestingly, we also found that participant misuse of formal authority is not a significant predictor of organizational success.

As we mentioned previously, we also found that the likelihood of misusing formal authority in inducing project failure will decrease by $63 \%$ with the mediation of informal leaders. The coefficient estimate decreases from -0.153 to -0.056 (table 5) when executives provide support to informal leaders. This finding further signifies the crucial roles of informal leaders in achieving success in IIS.

\section{DISCUSSION AND CONCLUDING REMARKS}

This section discusses our main findings and contrasts them with previous studies. It also proposes some implications for research and practice and explains the limitations of this study. Overall, we found that all three leadership variables have a statistically significant influence on the success of IIS initiatives.

\subsection{Recounting the Role Bureaucratic Leadership in IIS Success}

In 2007, Eglene et al., [8] proposed nine hypotheses and avenues for future research on the relationship between leadership and success in collaborative networks for information sharing. Four (4) out of their nine (9) hypotheses question the embeddedness of network leadership in bureaucratic environments and how it influences the success of information sharing networks. Pardo et al., [15] and Gil-Garcia et al., [10] expand this idea further by outlining three mechanisms comprising both bureaucratic-based and network-based leadership variables that influence the success of inter-organizational information sharing and integration through in-depth case studies. Based on these previous studies, this paper explores the roles of leadership activities in influencing the success of IIS using a quantitative analysis approach. We subsequently analyze the extent to which embeddedness in bureaucracy influences the relationship between leadership activities and the success of IIS based on a national survey in the US. Our findings are supportive and substantial in both questions. In particular, our findings provide clear support of the influence of bureaucratic leadership, in the form of executive involvement, in shaping the success of IIS initiatives.

Our findings supported and confirmed the propositions of Pardo et al., [15] and Gil-Garcia et al., [10] with regard to the direct and indirect influence of executive involvement in the success of IIS. The importance of executive involvement not only matters directly, for instance through provision of funding; but also indirectly through their support to informal leaders. The results also demonstrate that the support of executive involvement to the informal leaders is proven to be substantial. In fact, considering the standardized coefficient estimates, the influence of executive involvement to informal leaders is the most dominant in the model. Plausibly, this could be because the support from executives provides informal leaders with authority to act in the collaboration [8], which is particularly important because formal authority is developed gradually in networks [18].

Intriguingly, we also found the differences in coefficient estimates are influenced by the way success is measured. We found the smallest gap between the total effect and direct effects of executive involvement to the success of IIS when success is only measured as technological success, such as: integration of databases and creation of interoperable systems. Thus, even if executives confine their support to providing funding, the impact is similar to more extensive involvement such as supporting informal leaders when success is only measured technically.

In accordance to Pardo et al., [15] and Gil-Garcia et al., [10] propositions, our results indicate a strong and significant influence of executive involvement through informal leaders on the success of IIS initiatives. We found that involvement of executives in supporting informal leaders could even curb the negative impact of participant misuse of formal authority. Plausibly, informal leaders have more power to alleviate and mitigate the risk of participants misusing their formal authority if they have patronage from 
executives. As shown in the case of West Nile virus [10, 15], when executives show respect for the autonomy of participating organizations by considering the concerns of their peers in the collaboration, success is more likely to be achieved.

Overall, our findings, which strongly highlighted the role of executive involvement, demonstrate the bureaucracy effects on the success of inter-organizational information sharing and integration. Involvement of executives, embedded in bureaucratic positions ensures access not only to resources directly needed for the project but also for patronage which strengthened the positions and roles of informal leaders in implementing the projects [8].

\subsection{Confirming the Role of Informal Leaders}

The significant role of informal leaders for the success of a project that is managed in collaborative ways have become an established fact in the literature (see for instance: $1,2,11$ ) including inter-organizational information sharing and integration projects (see 4, 9, 10, 15, 23 and others). We also found strong direct influence of informal leaders on the success of IIS. More importantly, we found crucial roles of informal leaders in affecting the success indirectly. Of note, decreasing the negative effect of participant misuse of formal authority decreases the likelihood of a project's failure and increases the likelihood of success. In fact, if measured from the coefficient estimates (see Table 5), the ability of informal leaders to induce success by curbing the negative behavior of participants in misusing their formal authority is significant in increasing the likelihood of success. On the other hand, we found that the significance of the roles of informal leaders diminished when the success of a project is measured technically. The respondents deem the roles of informal leaders less important if a project success is only considered in technical terms. As discussed previously, in that situation, involvement of executives is perceived as more important.

\subsection{Implications and Limitations}

According to Eglene et al., [8], in a project that is managed through collaboration, success can be measured through various indicators. We found that depending on how project success is measured, the influence of leadership on that success is different. The main finding of this study have both research and practice implications.

\section{a. Practical Implications}

- We found that the significance of executive involvement varies depending on the specific measure of success. Thus, project managers in change of IIS projects could use these results for managing resources and involvement. For instance, if success is measured only technically, the total effect of executive involvement to success of IIS is more important than the total effect of informal leaders to the success of IIS. Especially when success is measured as policy and technical success. This knowledge could be used to better understand when executive involvement is more needed in IIS projects.

- We found patronage from executives to be a strong component in curbing negative behavior of participants in their exercise of formal authority. Consequently, extracting support from executives when the project is faced with conflict arising from misuse of formal authority would increase the probabilities of success in ISS projects.

- Our findings also indicate the roles of informal leaders in achieving success in IIS projects is crucial. As such, nurturing and encouraging informal leaders in IIS projects could significantly affect the success of those projects. However, it seems clear that when success is measured in technical terms only, informal leaders are less important.

b. Research Implications

- Our findings highlight how different leadership mechanisms influence the success of IIS. In particular, these leadership mechanisms are assumed by two actors: executives and informal leaders (project). Drake, Steckler \& Koch [7] argue that the enactment of leadership activities by leaders is affected by the sub-cultures. They adopt Schein's framework with three cultures (executive, engineer and operator - Schein [19]) into three comparable cultures in public sectors (scientist, politician and bureaucratic) [7]. Adopting from both, we can find comparable cultures affecting IIS projects as: politician, bureaucrats and project managers/informal leaders. We did not include these three sub-cultures into our models, but future research could test the influence of the leadership roles in IIS if mediated by their sub-cultures.

- In this study, we test Pardo et al., [15] and Gil-Garcia et al., [10] propositions by analyzing the influence of three leadership mechanisms - executive involvement, exercise of formal authority and informal leaders on the success of IIS projects. However, both Pardo et al., [15] and Gil-Garcia et al., [10] argue that the influence of these three mechanisms is mediated by other factors such as trust, willingness to participate, provision of funding, etc. While we take these mediating factors as granted in this study, future research could expand our models by including some mediating variables.

- Finally, we also found that participant misuse of formal authority is not a significant predictor of organizational success. This finding is intriguing to us. We posit that this might be due to, either, the measurement of organizational success or the definition of organization in IIS. Both warrant further research. For the former, we measure organizational success as a composite of five variables (see our methods section), thus future research could measure each variable as an indicator of success or find new indicators to define organizational success. For the latter, the definition of organization is ambiguous in IIS because it often involves multiple jurisdictions and levels of organizations. Further, there could be a mismatch between our indicators of organizational success and ambiguity in defining "organization" in IIS. Future research might address this issue for instance, by adding more control variables in the model defining boundaries in IIS initiatives.

\section{ACKNOWLEDGMENTS}

This work was partially supported by the National Science Foundation under Grant No. ITR-0205152. Any opinions, findings, and conclusions or recommendations expressed in this material are those of the authors and do not necessarily reflect the views of the National Science Foundation.

\section{REFERENCES}

[1] Balkundi, P. and Harrison, D. A.. 2006. Ties, Leaders, And Time In Teams: Strong Inference About Network Structure's Effects On Team Viability And Performance. Academy of 
Management Journal 49, 1: 49-68. http://doi.org/10.5465/AMJ.2006.20785500

[2] Balkundi, P. and Kilduff, M. 2006. The ties that lead: A social network approach to leadership. The Leadership Quarterly 17, 4: 419-439. http://doi.org/10.1016/j.leaqua.2006.01.001

[3] Dawes, S.S. 1996. Interagency information sharing: Expected benefits, manageable risks. Journal of Policy Analysis and Management 15, 3: 377-394.

[4] Dawes, S.S., Cresswell, A.M. and Pardo, T.A. 2009. From "need to know" to "need to share": Tangled problems, information boundaries, and the building of public sector knowledge networks. Public Administration Review 69, 3: 392-402.

[5] Dawes, S.S., and Pardo, T.A. 2002. Building Collaborative Digital Government Systems. In Advances in Digital Government, William J. McIver Jr and Ahmed K. Elmagarmid (eds.). Springer US, 259-273. Retrieved November 9, 2015 from http://link.springer.com/chapter/10.1007/0-306-473747_16

[6] Dawes, S.S., and Préfontaine, L. 2003. Delivering government services. Communications of the ACM 46, 1: 41.

[7] Drake, D.B., Steckler, N.A., and Koch, M.J. 2004. Information Sharing in and Across Government Agencies The Role and Influence of Scientist, Politician, and Bureaucrat Subcultures. Social Science Computer Review 22, 1: 67-84. http://doi.org/10.1177/0894439303259889

[8] Eglene, O., Dawes, S.S., and Schneider, C.A. 2007. Authority and leadership patterns in public sector knowledge networks. The American Review of Public Administration 37, 1: 91-113.

[9] Gil-Garcia, J.R., Guler, A., Pardo, T.A., and Burke, G.B. 2010. Trust in government cross-boundary information sharing initiatives: Identifying the determinants. System Sciences (HICSS), 2010 43rd Hawaii International Conference on, IEEE, 1-10. Retrieved November 10, 2015 from

http://ieeexplore.ieee.org/xpls/abs_all.jsp?arnumber=542834 1

[10] Gil-Garcia, J.R., Pardo, T.A., and Burke, G.B. 2007. Government leadership in multi-sector IT-enabled networks: Lessons from the response to the West Nile Virus outbreak. Workshop 4: Leading in a Multi-Sector Environment. Retrieved November 6, 2015 from http://ctg.albany.edu/publications/journals/government_leade rship/government_leadership.pdf

[11] Huxham, C. and Vangen, S. 2000. Leadership In The Shaping And Implementation Of Collaboration Agendas: How Things Happen In A (Not Quite) Joined-Up World. Academy of Management Journal 43, 6: 1159-1175. http://doi.org/10.2307/1556343

[12] Johnston, E.W., and Hansen. 2011. Design lessons for smart governance infrastructures. In Transforming American Governance: Rebooting the Public Square, Alan P. Balutis, Dwight Ink and Terry F. Buss (eds.). Routledge.
[13] Landsbergen, D., and Wolken, G. 2001. Realizing the Promise: Government Information Systems and the Fourth Generation of Information Technology. Public Administration Review 61, 2: 206-220.

[14] Pardo, T.A., Gil-Garcia, J.R. and Burke, G.B. 2006. Building response capacity through cross-boundary information sharing: The critical role of trust. In Exploiting the Knowledge Economy: Issues, Applications, Case Studies, P Cunningham and M Cunningham (eds.). 507-514. Retrieved November 10, 2015 from http://dev5.ctg.albany.edu/publications/journals/e2006_building_response/e-2006_building_response.pdf

[15] Pardo, T.A., Gil-Garcia, J.R., and Burke, G.B. 2007. Informal leadership and networks: Lessons from the response to the West Nile Virus outbreak. In Expanding the Knowledge Economy: Issues, Applications, Case Studies. IOS Press, Amsterdam. Retrieved November 6, 2015 from https://ctg.albany.edu/publications/journals/e2007_informal_leadership/e-2007_informal_leadership.pdf

[16] Pardo, T.A. and Tayi, G.K. 2007. Interorganizational information integration: A key enabler for digital government. Government Information Quarterly 24, 4: 691-715.

[17] Provan, K.G. and Milward, H.B. 2001. Do Networks Really Work? A Framework for Evaluating Public-Sector Organizational Networks. Public Administration Review 61, 4: 414-423. http://doi.org/10.1111/0033-3352.00045

[18] Rethemeyer, R.K., and Hatmaker, D.M. 2008. Network Management Reconsidered: An Inquiry into Management of Network Structures in Public Sector Service Provision. Journal of Public Administration Research and Theory 18, 4: 617-646. http://doi.org/10.1093/jopart/mum027

[19] Schein, E.H. 1996. Three cultures of management: The key to organizational learning. Sloan management review 38, 1: 9 20.

[20] Scholl, H.J. and Scholl, M.J.. 2014. Smart Governance: A Roadmap for Research and Practice. the iConference, IDEALS.

[21] Yang, T. and Maxwell, T.A. 2011. Information-sharing in public organizations: A literature review of interpersonal, intra-organizational and inter-organizational success factors. Government Information Quarterly 28, 2: 164-175.

[22] Zhang, J., Dawes, S.S., and Sarkis, J. 2005. Exploring stakeholders' expectations of the benefits and barriers of egovernment knowledge sharing. Journal of Enterprise Information Management 18, 5: 548-567. http://doi.org/10.1108/17410390510624007

[23] Zheng, L., Dawes, S.S., and Pardo, T.A. 2009. Leadership Behaviors in Cross-boundary Information Sharing and Integration: Comparing the US and China. Proceedings of the 3rd International Conference on Theory and Practice of Electronic Governance, ACM, 43-50. http://doi.org/10.1145/1693042.1693052 